\title{
Molecular and transcriptional characterization of phosphatidyl ethanolamine-binding proteins in wild peanuts Arachis duranensis and Arachis ipaensis
}

Hanqi Jin ${ }^{1}$, Xuemin Tang ${ }^{1}$, Mengge Xing ${ }^{1}$, Hong Zhu ${ }^{2}$, Jiongming Sui ${ }^{2}$, Chunmei Cai ${ }^{1}$ and Shuai Li $i^{*}$ (D)

\begin{abstract}
Background: Phosphatidyl ethanolamine-binding proteins (PEBPs) are involved in the regulation of plant architecture and flowering time. The functions of PEBP genes have been studied in many plant species. However, little is known about the characteristics and expression profiles of PEBP genes in wild peanut species, Arachis duranensis and Arachis ipaensis, the diploid ancestors of cultivated peanuts.

Results: In this study, genome-wide identification methods were used to identify and characterize a total of 32 peanut PEBP genes, 16 from each of the two wild peanut species, $A$. duranensis and A. ipaensis. These PEBP genes were classified into 3 groups (TERMINAL FLOWER1-like, FLOWERING LOCUS T-like, and MOTHER OF FT AND TFL1-like) based on their phylogenetic relationships. The gene structures, motifs, and chromosomal locations for each of these PEBPs were analyzed. In addition, 4 interchromosomal duplications and 1 tandem duplication were identified in A. duranensis, and 2 interchromosomal paralogs and 1 tandem paralog were identified in A. ipaensis. Ninety-five different cis-acting elements were identified in the PEBP gene promoter regions and most genes had different numbers and types of cis-elements. As a result, the transcription patterns of these PEBP genes varied in different tissues and under long day and short day conditions during different growth phases, indicating the functional diversities of PEBPs in different tissues and their potential functions in plant photoperiod dependent developmental pathways. Moreover, our analysis revealed that AraduF950M/AraduWY2NX in A. duranensis, and Araip344D4/ Araip4V81G in A. ipaensis are good candidates for regulating plant architecture, and that Aradu80YRY, AraduYY72S, and AraduEHZ9Y in A. duranensis and AraipVEP8T in A. ipaensis may be key factors regulating flowering time.
\end{abstract}

Conclusion: Sixteen PEBP genes were identified and characterized from each of the two diploid wild peanut genomes, A. duranensis and A. ipaensis. Genetic characterization and spatio-temporal expression analysis support their importance in plant growth and development. These findings further our understanding of PEBP gene functions in plant species.

Keywords: Wild peanut, Phosphatidyl ethanolamine-binding protein (PEBP), Gene family, Flowering time, Plant architecture

\footnotetext{
* Correspondence: li2014shuai@qau.edu.cn

${ }^{1}$ College of Life Sciences, Key Lab of Plant Biotechnology in Universities of

Shandong Province, Qingdao Agricultural University, Qingdao 266109, China

Full list of author information is available at the end of the article
}

(c) The Author(s). 2019 Open Access This article is distributed under the terms of the Creative Commons Attribution 4.0 International License (http://creativecommons.org/licenses/by/4.0/), which permits unrestricted use, distribution, and reproduction in any medium, provided you give appropriate credit to the original author(s) and the source, provide a link to the Creative Commons license, and indicate if changes were made. The Creative Commons Public Domain Dedication waiver (http://creativecommons.org/publicdomain/zero/1.0/) applies to the data made available in this article, unless otherwise stated. 


\section{Background}

Flowering time is a critical factor influencing the production of offspring in plants. Thus, plants have evolved complex systems regulating the transition from the vegetative to the reproductive phase. The precise adjustment of flowering time is controlled by both internal and environmental cues [1-4]. Several pathways regulating flowering time have been identified, such as photoperiod, vernalization, giberellic acid, and autonomous pathways [1, 2, 5-7]. Moreover, numerous molecular regulatory components have been shown to participate in these flowering regulatory pathways. For example, many MADS-box family members and phosphatidyl ethanolamine-binding proteins (PEBPs) have been shown to participate in the switch from the shoot apical meristem to the inflorescence meristem $[1,8,9]$.

The PEBP gene family is an ancient, conserved set of genes encoding proteins that are highly similar in all eukaryote kingdoms, including bacteria, animals, and plants [10-12]. PEBPs were identified by their preference for binding phosphatidyl ethanolamine lipids over other phospholipids [13]. Previous investigation into the functions of PEBP genes revealed that PEBPs encode proteins that are involved in multiple signal pathways regulating growth and differentiation in many species $[12,14,15]$. In plants, $P E B P$ genes mainly participate in flowering time and plant architecture regulation [11, 16, 17]. Many recent studies have investigated individual $P E B P$ genes, however, the complete $P E B P$ family has been studied in only a few plant species, such as Arabidopsis, soybean, rice, maize, and cotton $[8,18-20]$.

In plants, $P E B P$ family genes are generally classified into three groups: TERMINAL FLOWER1 (TFL1)-like, FLOWERING LOCUS T (FT)-like, and MOTHER OF FT AND TFL1 (MFT)-like sub-families [1, 8, 18, 21, 22]. In Arabidopsis, the $F T$-like sub-family contains two members, FT and TWIN SISTER OF FT (TSF), both of which promote the transition from vegetative to reproductive growth $[1,23,24] . F T$ is a circadian clock gene, and its protein has been shown to move from the leaves to the shoot apical meristem and interact with the transcription factor FD to accelerate flowering [25-29]. TSF, the closest homolog of $F T$, has similar functions. Overexpression of TSF promotes flowering and tsf mutants have delayed flowering time phenotypes [1,30]. The TFL1-like subfamily has three members, TFL1, Arabidopsis thaliana CENTRORADIALIS (ATC), and BROTHER OF FT $(B F T)$, all of which have been reported to delay flowering time. TFL1 is involved in the regulation of flowering time and plant architecture. Mutation of TFL1 causes early flowering time and determinate growth habit $[1,31]$. ATC is a short-day induced floral inhibitor, and its protein travels through the vasculature to the shoot apex to influence flowering time [1,32]. BFT shows a diurnally oscillating expression pattern that peaks in the early evening, similar to $F T$. Overexpression of BFT causes delayed flowering time and severe floral defects, while knockdown of BFT has no effect on flowering time. Thus, BFT works redundantly in the determination of flowering time [1,33]. The $M F T$-like sub-group contains only one member, $M F T$, which has weak $F T$-like activity and mainly participates in the seed germination signal pathway $[34,35]$.

Peanut is an important oil legume throughout the world. The cultivated peanut is an allotetraploid (AABB, $2 n=4 x=40)$ and is thought to have been derived from hybridization and polyploidization of two diploid species, A. duranensis (AA genome) and A. ipaensis (BB genome) [36-39]. Improving plant architecture and flowering time could help to increase peanut production. Analysis of functional genes can help identify modifications that can be made to peanut cultivars in order to increase yields. The investigation of wild peanut genes will provide essential information for further functional characterization of cultivated peanut genes [40, 41]. In this study, $P E B P$ genes were identified and characterized from two wild peanut species, $A$. duranensis and $A$. ipaensis. Many characteristics of these PEBP genes were analyzed, including gene evolutionary relationships, gene structures, conserved motifs, and gene expression patterns. Our findings will enable further characterization of $P E B P$ gene and protein functions in peanuts.

\section{Methods}

\section{Plant materials and growth conditions}

Wild A. duranensis PI219823 and A. ipaensis PI468322 species were used for gene expression analysis. Peanut seeds were germinated in tap water and then planted in pots in growth chambers with different photoperiods. The growth conditions were set as $16 \mathrm{~h} 24{ }^{\circ} \mathrm{C}$ light $/ 8 \mathrm{~h}$ $24{ }^{\circ} \mathrm{C}$ dark and $10 \mathrm{~h} 24^{\circ} \mathrm{C}$ light $/ 14 \mathrm{~h} 24^{\circ} \mathrm{C}$ dark cycles for long day and short day photoperiods, respectively. The humidity was controlled at approximately $30 \%$. Plant leaves were sampled $2 \mathrm{~h}$ after lights-on at different growth stages. Stage 1 to stage 6 (S1-S6) were considered to be when the first two, the third, the fourth, the fifth, the sixth, and the seventh leaves were fully expanded, respectively. To confirm the expression levels of $P E B P$ genes in different tissues, the cultivated peanut Tiffrunner and wild peanuts were grown in the field in Qingdao, China, and different tissues were collected for analysis. The samples were stored at $-80^{\circ} \mathrm{C}$ before RNA extraction.

\section{Identification of peanut PEBP members}

The amino acid sequence of the PEBP conserved domain (PF01161) and PEBP amino acid sequences from Arabidopsis [1] and soybean [8] were used as blast queries against the peanut genome database (https://www.peanutbase.org/). All 
output genes were analyzed using the Pfam database (http://pfam.xfam.org/search) and the National Center for Biotechnology Information (NCBI) in order to confirm the conserved PEBP domains. Genes without conserved domain sequences were discarded. The protein molecular weight and theoretical iso-electric points were determined using ProtParam (https://web.expasy.org/protparam/). The subcellular localizations of PEBPs were predicted using the ProtComp tool (http://linux1.softberry.com/ berry.phtml?topic $=$ protcomppl\&group=programs \&subgroup $=$ proloc).

\section{Phylogenetic relationship analysis}

The full-length PEBP amino acid sequences from two wild peanut species, cultivated peanut, Arabidopsis, soybean, common bean, and medicago [8] were aligned using Clustal-X2. The alignment results were used to construct a phylogenetic tree using the Neighbor-Joining method in MEGA 7 [42, 43].

\section{Analyses of PEBP gene structures and conserved motifs} The exon-intron organizations of wild peanut PEBPS were determined with the Gene Structure Display Server program (GSDS) using the coding domain sequences (CDS) and genomic sequences obtained from the peanut genome database [44]. The peanut PEBP conserved motifs were analyzed using MEME tools (http://memesuite.org/) with the following parameters: a maximum number of 15 motifs and an optimum motif width of 650 amino acid residues.

\section{Analyses of chromosomal localization, gene duplication, synteny, and cis-acting elements}

To analyze chromosomal distribution, PEBP gene positions were obtained from the peanut genome database and mapped to the physical chromosome positions. Synteny analysis between the soybean, the common bean, and the peanut was carried out as described by Zhang et al. [45]. To analyze gene duplication, peanut PEBP sequences were clustered using OrthoMCL software and homologous relationships were determined using the Circos software $[46,47]$. The cis-acting elements of peanut PEBP genes were predicted by PlantCARE (http:// bioinformatics.psb.ugent.be/webtools/plantcare/html/) [48], using the promoter regions $2 \mathrm{~kb}$ upstream of the translation initiation codons of each $P E B P$ gene.

\section{Subcellular localization analysis}

The subcellular localizations of representative wild peanut $P E B P$ genes were analyzed as described by Li et al. [49]. Each full-length PEBP gene and GFP were amplified and cloned into modified pCAMBIA1300 vectors. The constructs were then transiently expressed in
Nicotiana benthamiana leaves using the Agrobacteriummediated infiltration method.

\section{RNA extraction and expression analysis}

RNA extraction and quantitative real-time PCR (qRTPCR) were performed as described by $\mathrm{Li}$ et al. [49]. Briefly, RNeasy mini kits (Qiagen) were used to isolate total plant RNA. First-strand cDNAs synthesis was performed using SuperScript II reverse transcriptase (Promega) and $1.5 \mu \mathrm{g}$ total RNA from each sample. qRT-PCR was performed with a LightCycler480 machine (Roche Diagnostics) using LightCycler 480 SYBR Green I Master Kit (Roche Diagnostics). The qRT-PCR amplification program was as follows: $94{ }^{\circ} \mathrm{C}$ for $10 \mathrm{~s}, 58^{\circ} \mathrm{C}$ for $10 \mathrm{~s}$, and $72{ }^{\circ} \mathrm{C}$ for $10 \mathrm{~s}$, for 40 cycles. The gene expression levels were normalized to the wild peanut Actin-expressing gene (AraduW2Y55 or AraipFY50U). For gene expression analysis in the cultivated peanut, gene expression levels were normalized to the Actin-expressing gene, as described by Sui et al. [50]. Each sample was analyzed using three biological replicates. All the primers used in this study are listed in Additional file 10. To determine the transcription patterns of $P E B P$ genes in various tissues, the RNA-seq datasets of 22 different tissues from cultivated peanut were obtained from the peanut database (https://peanutbase.org/gene_expression). The 22 tissues were identified as described by Clevenger et al. [51] and are as follows: 'Seedling Leaves' (seedling leaves 10 days after emergence), 'Main Stem Leaves', 'Lateral Stem Leaves', 'Vegetative Shoot Tip' (from the main stem), 'Reproductive Shoot Tip' (from the first lateral leaf), 'Roots' (10 day-old roots), 'Nodule Roots' (25 day-old nodules), 'Flowers' (perianth), 'Pistils' (gynoecium), 'Stamens' (androecium), 'Aerial Gyn Tip' (aerial gynophore tip), 'Sub Gyn Tip' (subterranean gynophore tip), 'PodPt1' (pattee stage 1 pod), 'StalkPt1' (pattee stage 1 stalk), 'PodPt3' (pattee stage 3 pod), 'Pericarp Pattee5' (pattee stage 5 pericarp), 'Seed Pattee5' (pattee stage 5 seed), 'Pericarp Pattee6' (pattee stage 6 pericarp), 'Seed Pattee6' (pattee stage 6 seed), 'Seed Pattee7' (pattee stage 7 seed), 'Seed Pattee8' (pattee stage 8 seed), and 'Seed Pattee10' (pattee stage 10 seed). The $A$. hypogaea gene expression profiles were mapped to $A$. duranensis and $A$. ipaensis for heat map analysis [51-53].

\section{Results}

Identification of $P E B P$ genes in two wild peanut species To identify $P E B P$ genes expressed in the wild peanut species $A$. duranensis and $A$. ipaensis, the amino acid sequences of the PEBP conserved domain (PF01161) and the full-length PEBP protein sequences from Arabidopsis and soybean were used as blast queries against the peanut genome database. Pfam and NCBI tools were then used to confirm the conserved PEBP domains in these 
candidate $P E B P$ genes. In total, 32 PEBP genes were identified from the two wild peanut genomes (Table 1). Multiple $P E B P$ gene characteristics were analyzed using the genomic, CDS, and amino acid sequences (Table 1). The genomic lengths of wild peanut $P E B P$ genes ranged from $989 \mathrm{bp}$ (AraduP7QP3) to $8770 \mathrm{bp}$ (AraduWY2NX), CDS lengths ranged from $327 \mathrm{bp}$ (AraduWY2NX) to $630 \mathrm{bp}$ (Ara$d u G 0 N J W)$, and the deduced number of amino acids ranged from 108 to 209. The molecular weights and isoelectric points for each PEBP were predicted (AraduG0NJW was discarded due to lack of related information). The molecular weights ranged from 12,058.74 to
20,482.26 $\mathrm{kDa}$ and the isoelectric points ranged from 4.93 to 9.68. In addition, the PEBP sub-cellular localizations were predicted. No information was found about the localization of Aradu23179, Aradu60NUI, or AraipV0B0S. All other wild peanut PEBPs were predicted to be localized in both the cytoplasm and the nucleus (Table 1), similar to soybean PEBPs [8]. The subcellular localizations of several PEBPs in $A$. duranensis, including AraduWY2NX, AraduYY72S, and AraduQIZ46, and in A. ipaensis, including Araip4V81G, AraipVEP8T and AraipA8S33 were identified. The results confirmed their subcellular localizations in cytoplasm and nucleus (Additional file 1).

Table 1 PEBP members identified from two wild peanut species

\begin{tabular}{|c|c|c|c|c|c|c|c|c|}
\hline Gene ID & Chr & Genomic Length (bp) & CDS Length(bp) & No. of $A A$ & Mol.Wt (kDa) & $\mathrm{pl}$ & Subcellular Localization & Gene Family \\
\hline AraduEHZ9Y & $\mathrm{A} 02$ & 5124 & 507 & 168 & $18,645.2$ & 6.9 & Cytoplasm and Nucleus & FT-like \\
\hline Aradu23179 & $\mathrm{A} 02$ & 1027 & 510 & 169 & $18,629.02$ & 5.37 & $\mathrm{~N} / \mathrm{A}$ & MFT-like \\
\hline Aradu60NUI & $\mathrm{A} 02$ & 1439 & 528 & 175 & $19,629.32$ & 4.93 & $N / A$ & MFT-like \\
\hline AraduF950M & $\mathrm{A} 02$ & 1985 & 444 & 147 & $16,315.35$ & 6.57 & Cytoplasm and Nucleus & TFL1-like \\
\hline AraduZ8JSI & A03 & 4282 & 531 & 176 & $19,253.3$ & 8.57 & Cytoplasm and Nucleus & MFT-like \\
\hline AraduA9H9T & $\mathrm{A} 04$ & 1968 & 543 & 180 & $20,293.04$ & 6.51 & Cytoplasm and Nucleus & FT-like \\
\hline AraduA4ISL & $\mathrm{A} 04$ & 2826 & 543 & 180 & $20,473.5$ & 7.86 & Cytoplasm and Nucleus & FT-like \\
\hline Aradu117E9 & $\mathrm{A} 04$ & 1175 & 534 & 177 & $19,831.56$ & 6.73 & Cytoplasm and Nucleus & FT-like \\
\hline AraduP7QP3 & A05 & 989 & 486 & 161 & $18,175.77$ & 9.15 & Cytoplasm and Nucleus & TFL1-like \\
\hline AraduWY2NX & A06 & 8770 & 327 & 108 & $12,058.74$ & 5.14 & Cytoplasm and Nucleus & TFL1-like \\
\hline Aradu80YRY & A06 & 1984 & 537 & 178 & $19,874.48$ & 8.54 & Cytoplasm and Nucleus & FT-like \\
\hline AraduA6WCN & A08 & 3143 & 489 & 162 & $18,224.68$ & 9.12 & Cytoplasm and Nucleus & FT-like \\
\hline AraduRJP5K & $\mathrm{A} 08$ & 1296 & 495 & 164 & $18,620.2$ & 9.21 & Cytoplasm and Nucleus & TFL1-like \\
\hline AraduQIZ46 & A10 & 2030 & 537 & 178 & $19,345.85$ & 7.8 & Cytoplasm and Nucleus & MFT-like \\
\hline AraduGONJW & A10 & 3071 & 630 & 209 & N/A & N/A & Cytoplasm and Nucleus & FT-like \\
\hline AraduYY72S & A10 & 1652 & 519 & 172 & $19,688.48$ & 8.9 & Cytoplasm and Nucleus & FT-like \\
\hline AraipVOBOS & B02 & 1134 & 510 & 169 & $18,692.12$ & 5.37 & N/A & MFT-like \\
\hline Araip344D4 & B02 & 1513 & 432 & 143 & $16,183.4$ & 9.62 & Cytoplasm and Nucleus & TFL1-like \\
\hline AraipWF9GZ & B03 & 4518 & 531 & 176 & $19,248.28$ & 8.93 & Cytoplasm and Nucleus & MFT-like \\
\hline AraipPC28F & B04 & 1810 & 543 & 180 & $20,391.15$ & 6.58 & Cytoplasm and Nucleus & FT-like \\
\hline AraipU9HL1 & B04 & 2806 & 525 & 174 & $19,750.6$ & 6.9 & Cytoplasm and Nucleus & FT-like \\
\hline AraipT1SIZ & B04 & 1298 & 534 & 177 & $19,845.59$ & 6.73 & Cytoplasm and Nucleus & FT-like \\
\hline AraipYA5YU & B05 & 6384 & 531 & 176 & $19,780.57$ & 6.82 & Cytoplasm and Nucleus & FT-like \\
\hline AraipA5PDN & B05 & 995 & 486 & 161 & $18,153.78$ & 9.15 & Cytoplasm and Nucleus & TFL 1-like \\
\hline Araip4V81G & B06 & 1414 & 417 & 138 & $15,444.45$ & 6.05 & Cytoplasm and Nucleus & TFL1-like \\
\hline AraipZJ9GZ & B06 & 4212 & 546 & 181 & $20,482.26$ & 9.04 & Cytoplasm and Nucleus & FT-like \\
\hline AraipV23ZE & B06 & 1446 & 441 & 146 & $16,362.59$ & 9.68 & Cytoplasm and Nucleus & FT-like \\
\hline Araip03WUR & B07 & 2576 & 498 & 165 & $18,585.18$ & 6.82 & Cytoplasm and Nucleus & FT-like \\
\hline AraipT6XJY & B08 & 1387 & 543 & 180 & $20,385.32$ & 9.24 & Cytoplasm and Nucleus & TFL1-like \\
\hline AraipWWI38 & B09 & 2632 & 522 & 173 & $19,214.79$ & 7.82 & Cytoplasm and Nucleus & FT-like \\
\hline AraipA8S33 & B10 & 1766 & 537 & 178 & $19,495.09$ & 8.53 & Cytoplasm and Nucleus & MFT-like \\
\hline AraipVEP8T & B10 & 1535 & 522 & 173 & $19,275.74$ & 6.83 & Cytoplasm and Nucleus & FT-like \\
\hline
\end{tabular}




\section{Chromosomal localization analysis}

To determine the chromosomal locations of wild peanut PEBPs, the PEBP genes were mapped to the related chromosome positions using the peanut genome database (Fig. 1). The chromosome distribution map revealed the positions of the 16 PEBP genes from each of the two wild peanut species (Fig. 1 and Table 1). For the AA genome wild specie, $P E B P$ genes were distributed on 7 of the 10 chromosomes and no PEBP genes were found on chromosome 1, 7, or 9. Chromosome 2 contained the most $P E B P$ genes, 4 in total (Fig. 1). In contrast, 9 of the 10 chromosomes in the $\mathrm{BB}$ wild peanut genome contained $P E B P$ genes, all except for chromosome 1. Chromosomes 4 and 6 contained the most $P E B P$ genes in the $\mathrm{BB}$ genome, with 3 PEBP genes on each (Fig. 1). Among these $P E B P$ genes, most were located in the chromosome arms (Fig. 1). Only four genes, including AraduWY2NX, AraduRJP5K, AraduG0NJW, and Araip4V81G, were found close to the middle of the chromosome (Fig. 1).

\section{Classification and phylogenetic analysis of PEBP genes} In plants, $P E B P$ genes can be grouped into 3 sub-families, TFL1-like, FT-like, and MFT-like, according to their gene structures $[1,8]$. To classify the wild peanut PEBP genes into different sub-families and infer information based on the well-studied homologous $P E B P$ genes from other plant species, a phylogenetic tree was constructed using $P E B P$ genes from wild peanuts, Arabidopsis, soybean, common bean, and medicago [8]. The phylogenetic relationship analysis classified the wild peanut PEBP genes into 3 subfamilies (Fig. 2 and Table 1). Among these members, 8 PEBP genes belonged to the TFL1-like sub-family, 17 members were grouped into the $F T$-like sub-family, and 7 PEBPS were classified into the $M F T$-like sub-family. The AA genome contained $8 F T$-like, 4 TFL1-like, and $4 M F T$-like genes. In contrast, the BB genome had $9 F T$-like, 4 TFL1like, and $3 M F T$-like members, likely reflecting the functional differentiation of genes in the $\mathrm{AA}$ and $\mathrm{BB}$ genomes. Because the cultivated peanut is an allotetraploid derived from hybridization and polyploidization of $A$. duranensis and A. ipaensis, cultivated peanut (A. hypogaea) PEBP genes were also investigated and 31 PEBP members were identified (Additional file 2). Phylogenetic analysis revealed that the A. hypogaea genome contained 8 TFL1-like, 16 $F T$-like, and 7 MFT-like members (Additional file 2).

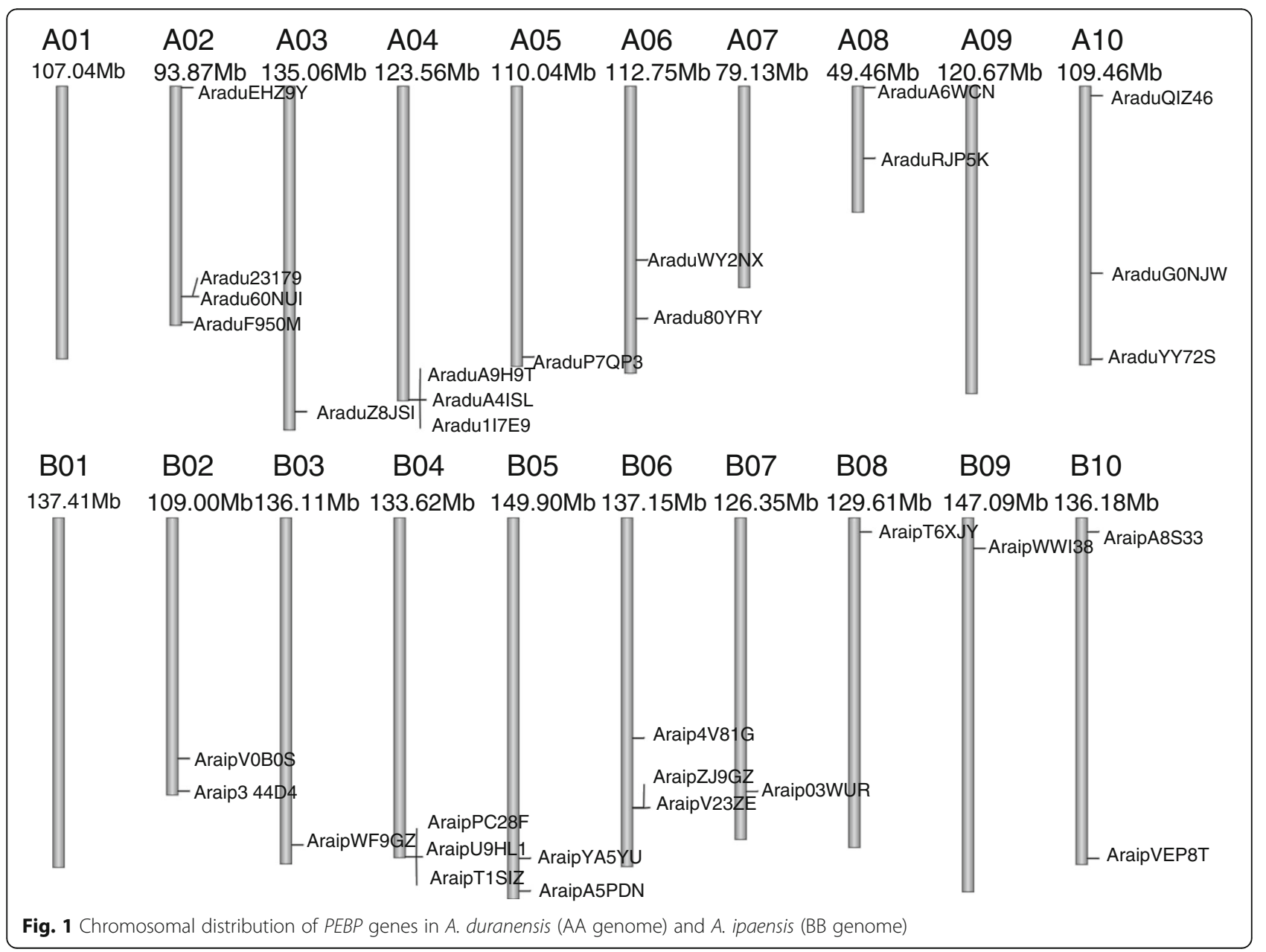




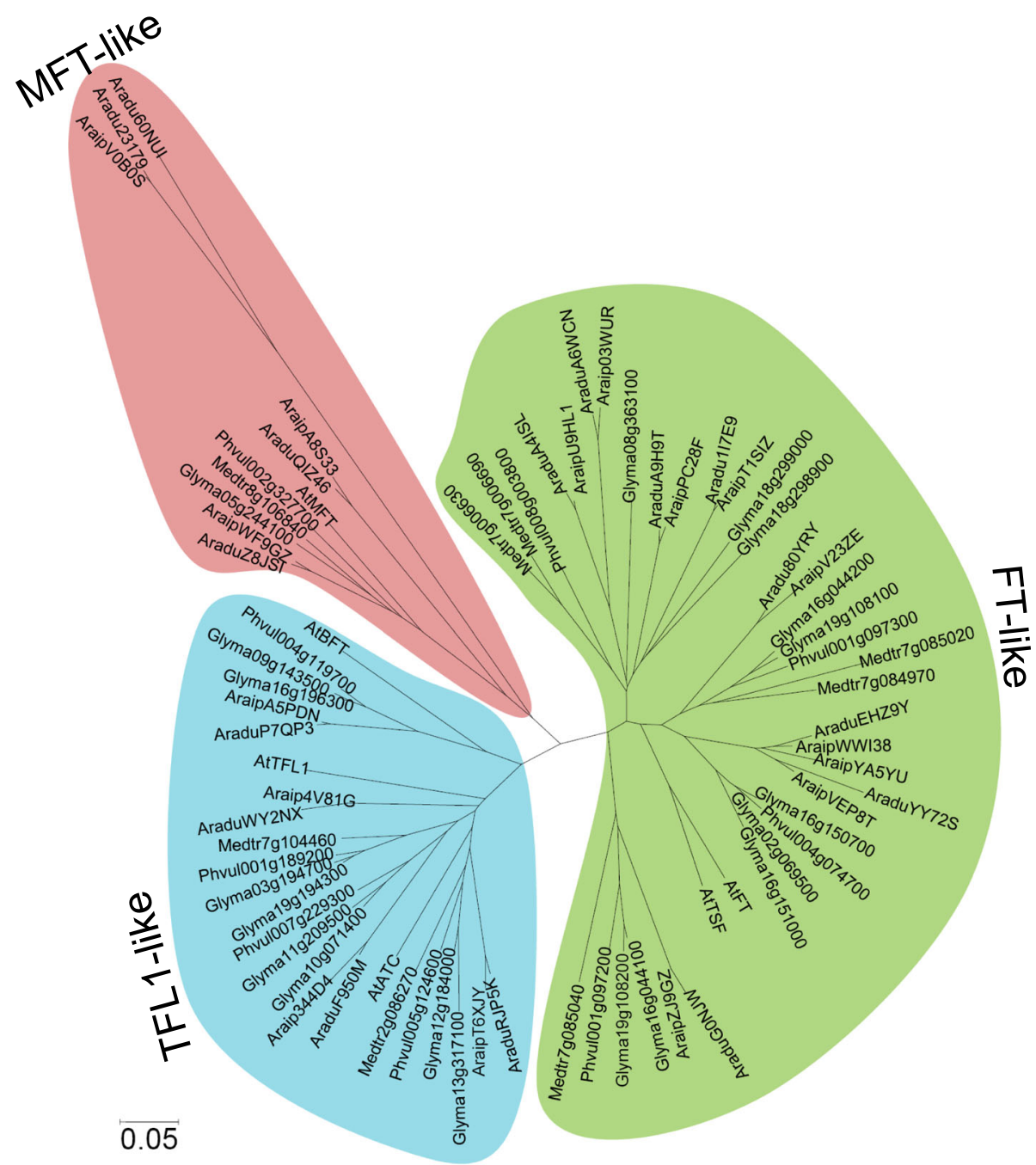

Fig. 2 Evolutionary relationship analysis of PEBP proteins from two wild peanut species. PEBP amino acid sequences from wild peanut species, Arabidopsis, soybean, common bean, and medicago were used to construct a phylogenetic tree

Many orthologous gene pairs have been identified between the AA and BB genomes in wild peanuts [40, 41, 54, 55]. Thus, orthologous PEBP gene pairs were investigated using a phylogenetic tree generated with wild peanut PEBP amino acid sequences (Fig. 3a). Fifteen orthologous PEBP gene pairs (all except for AraipYA5YU and Aradu60NUI) were classified into the same cluster (Fig. 3a). Most of the gene pairs have highly similar CDS and protein sequences (Fig. 3a, and Table 2), suggesting that orthologous genes have similar functions. Chromosomal localization analysis showed that 11 of the 15 orthologous gene pairs were found on the syntenic locus of $A$. duranensis and A. ipaensis chromosomes (Fig. 1 and Table 2). However, AraduEHZ9Y, AraduA6WCN, and AraduGONJW were found to be located on different chromosomes than their related orthologous genes in A. ipaensis. AraduRJP5K was located in the middle part of chromosome 8 , while its orthologous gene, AraipT6XJY, was located in the chromosome arm (Fig. 1 and Table 2). This suggests that chromosomal rearrangement might have occurred in the diploid peanut genomes $[54,56]$.

\section{Exon-intron structures and conserved domains of PEBP genes}

Classical PEBP members have a conserved 4-exon gene structure [19]. To determine the gene structures of wild peanut $P E B P$ genes, the Gene Structure Display Server program was used to investigate $P E B P$ exon-intron organizations [44]. Our findings revealed that 23 of the 32 PEBP members had the 4-exon conserved gene structure, while 9 genes displayed inconsistent organization (Fig. 3b). For these 9 genes, the FT-like members AraduEHZ9Y, Aradu80YRY, AraipV23ZE, and AraipZJ9GZ 


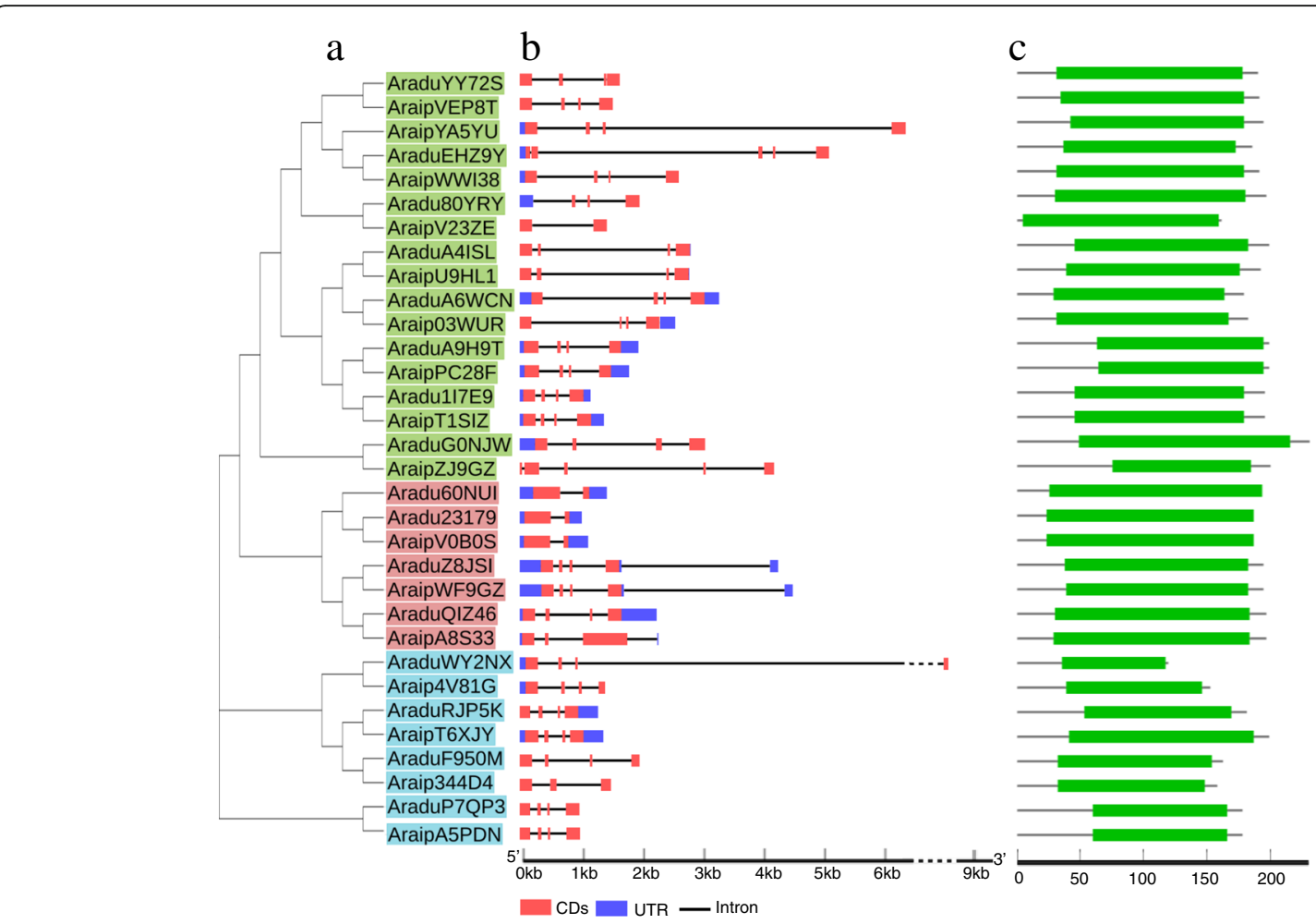

Fig. 3 Phylogenetic and structure analysis of PEBP genes from two wild peanut species. a Phylogenetic relationship analysis of wild peanut PEBP proteins. The green, pink, and light blue colors indicate TFL 1-like, MFT-like, and FT-like sub-families, respectively. b The exon-intron organizations of PEBP genes. UTRs, exons, and introns are represented by dark blue, red, and black lines, respectively. c The green boxes indicate conserved PEBP domains in each of the different peanut PEBP proteins

Table 2 AdPEBP and AiPEBP orthologous genes

\begin{tabular}{|c|c|c|c|c|}
\hline Gene pairs & Groups & Chr & $\begin{array}{l}\text { CDS } \\
\text { Identity (\%) }\end{array}$ & $\begin{array}{l}\text { Protein } \\
\text { Identity (\%) }\end{array}$ \\
\hline AraduYY72S-AraipVEP8T & FT-like-FT-like & A10-B10 & $93.06 \%$ & $89.60 \%$ \\
\hline AraduEHZ9Y-AraipWWI38 & FT-like-FT-like & A02-B09 & $93.64 \%$ & $91.91 \%$ \\
\hline Aradu80YRY-AraipV23ZE & FT-like-FT-like & A06-B06 & $97.41 \%$ & $77.53 \%$ \\
\hline AraduA4ISL-AraipU9HL1 & FT-like-FT-like & A04-B04 & $97.90 \%$ & $97.70 \%$ \\
\hline AraduA6WCN-Araip03WUR & FT-like-FT-like & A08-B07 & $93.78 \%$ & $93.33 \%$ \\
\hline AraduA9H9T-AraipPC28F & FT-like-FT-like & A04-B04 & $97.97 \%$ & $97.22 \%$ \\
\hline Aradu1I7E9-AraipT1SIZ & FT-like-FT-like & A04-B04 & $98.31 \%$ & $98.87 \%$ \\
\hline AraduGONJW-AraipZJ9GZ & FT-like-FT-like & A10-B06 & $98.57 \%$ & $74.16 \%$ \\
\hline Aradu23179-AraipVOBOS & MFT-like-MFT-like & $\mathrm{A} 02-\mathrm{B} 02$ & $97.65 \%$ & $98.22 \%$ \\
\hline AraduZ8JSI-AraipWF9GZ & MFT-like-MFT-like & A03-B03 & $96.80 \%$ & $96.59 \%$ \\
\hline AraduQIZ46-AraipA8S33 & MFT-like-MFT-like & A10-B10 & $96.65 \%$ & $94.94 \%$ \\
\hline AraduP7QP3-AraipA5PDN & TFL1-like-TFL1-like & A05-B05 & $98.35 \%$ & $98.14 \%$ \\
\hline AraduWY2NX-Araip4V81G & TFL 1-like-TFL1-like & A06-B06 & $99.35 \%$ & $96.30 \%$ \\
\hline AraduRJP5K-AraipT6XJY & TFL 1-like-TFL1-like & A08-B08 & $96.62 \%$ & $88.20 \%$ \\
\hline AraduF950M-Araip344D4 & TFL 1-like-TFL 1-like & $\mathrm{A} 02-\mathrm{B} 02$ & $92.79 \%$ & $91.16 \%$ \\
\hline
\end{tabular}

Chr chromosome number 
contained 5, 3, 2, and 5 exons, respectively. The $M F T$-like genes Aradu60NUI, Aradu23197, AraduvOBOS, and AraipA8S33 had 2, 2, 2, and 3 exons, respectively, and the TFL1-like gene Araip344D4 had 3 exons (Fig. 3b). In addition, the PEBP domains in each of the wild peanut PEBPs were analyzed and the lengths of the PEBP domains were found to be more than half of each PEBP protein, except for AraipZJ9GZ (Fig. 3c and Additional file 3). To further analyze PEBP structures, the conserved motifs of PEBP proteins were investigated. Fifteen distinct motifs were found in the 32 wild peanut PEBPs (Fig. 4 and Additional file 4). However, no single motif was found on all PEBP proteins, indicating their function diversity.

\section{Analysis of PEBP gene duplication and synteny}

Polyploidy is common in flowering plants, and gene duplication often occurs during gene evolution [57], thus a homology analysis of the wild peanut genomes was performed. Many paralogous genes were found in both A. duranensis and A. ipaensis (Fig. 5). Four interchromosomal duplications and one tandem duplication were identified in $A$. duranensis. Three interchromosomal duplications, AraduYY72S/AraduEHZ9Y, Aradu80YRY/
AraduEHZ9Y, and AraduA6WCN/AraduA4ISL, belonged to the $F T$-like sub-family and AraduWY2NX/AraduF950M belonged to the TFL1-subfamily. The tandem duplication was composed of three genes: AraduA9H9T, AraduA4ISL, and Aradu1I7E9. Two interchromosomal paralogs, AraipWWI38/AraipVEP8T and AraipWWI38/ Araip $Y A 5 Y U$, and one tandem duplication were found in $A$. ipaensis. The two duplicated gene pairs belonged to the $F T$-like sub-class, and the tandem paralog contained three members: AraipPC28F, AraipT1SIZ, and AraipU9HL1. In addition, a homology analysis was also perfomed between A. duranensis and A. ipaensis and 25 homologous gene pairs were identified. Among these gene pairs, the tandem duplicates AraduA9H9T, AraduA4ISL, and Aradu1I7E9 in $A$. duranensis were found to be homologous with the tandem paralogs AraipPC28F, AraipT1SIZ, and AraipU9HL1 in A. ipaensis (Fig. 5).

Arabidopsis TFL1 regulates plant architecture and its homologous genes in legumes are syntelogs with conserved functions $[1,58-61]$. To investigate the potential functions of wild peanut TFL1-like genes, the genomic regions surrounding soybean growth habit gene GmDt1 (Glyma19g194300), common bean growth

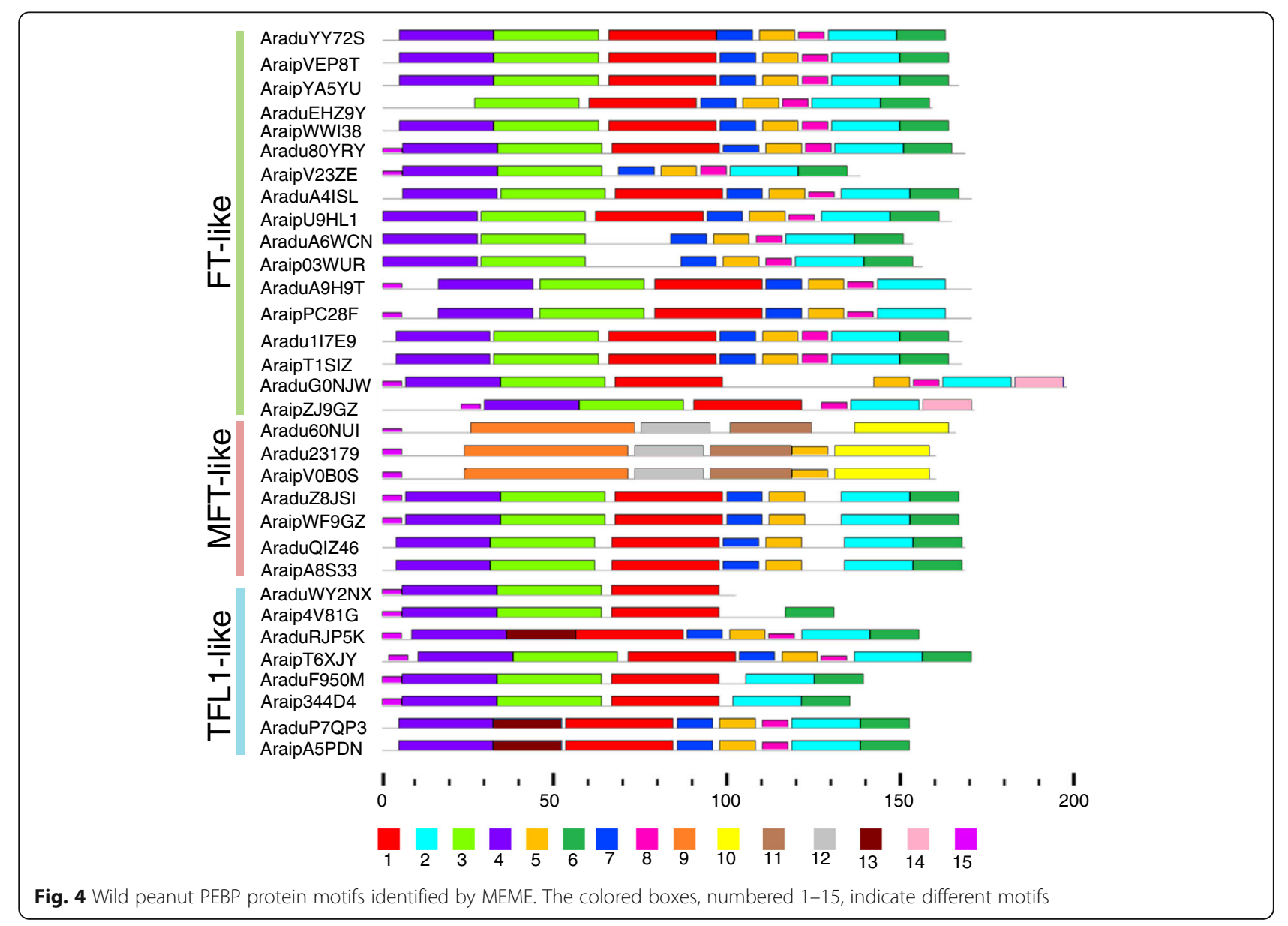




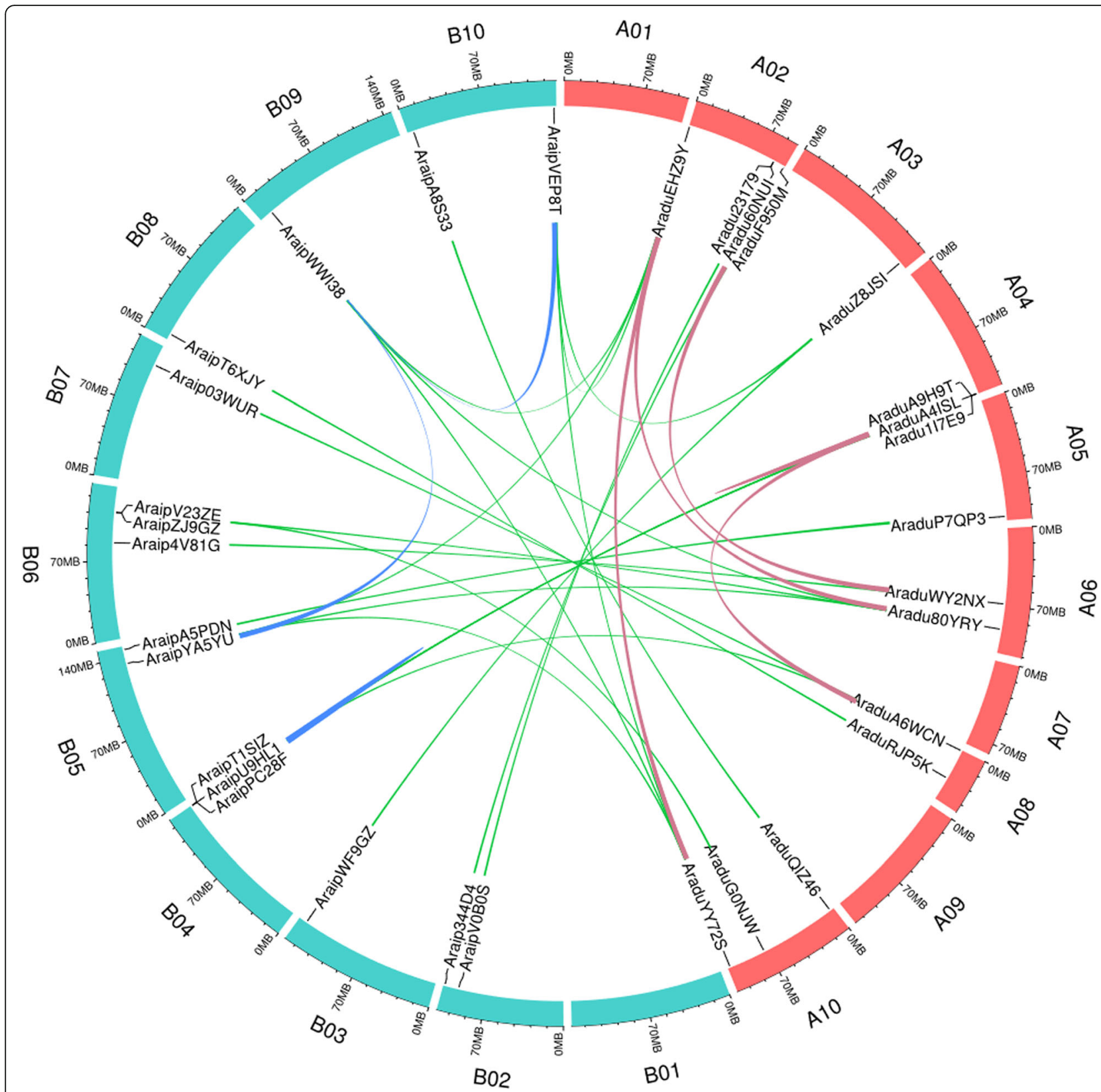

Fig. 5 Homology analysis of A. duranensis and A. ipaensis PEBP genes. Green lines indicate homologous gene pairs between A. duranensis and A. ipaensis. Red lines indicate duplicated gene pairs in A. duranensis and blue lines indicate duplication events in A. ipaensis

habit gene PvTFL1y (Phvul001g189200), and wild peanut TFL1 homologs were compared to determine whether they were syntelogs. Syntenys between wild peanut genes AraduF950M, AraduWY2NX, Araip344D4, Araip4V81G, soybean GmDt1, and common bean PvTFL1y were found in all regions compared (Additional file 5), indicating that these genes may have evolved from the same origin and that these wild peanut genes might participate in plant architecture regulation.
Analysis of cis-acting elements in wild peanut PEBP gene promoter regions

To investigate the regulation of wild peanut PEBP gene expression, cis-acting elements in the promoter regions $2 \mathrm{~kb}$ upstream of the translation initiation codons were analyzed. In total, 95 types of cis-acting elements were found upstream of these PEBP genes, of which 56 were predicted to have putative functions, including 7 development related elements, 4 environmental stress related elements, 10 hormone-responsive elements, 26 light- 
responsive elements, 5 promoter related elements, and 4 site-binding related elements (Table 3 and Additional file 6). Among these functional cis-acting elements, the lightresponsive elements were the most abundant type in each PEBP promoter, and all of the PEBP genes contained hormone-responsive elements, light-responsive elements, and promoter related elements, suggesting that all of the PEBPs are involved in related signaling pathways (Table 3). Moreover, the promoter-related element TATA-box was found in all 32 wild peanut $P E B P$ promoter regions, suggesting that the TATA-box is necessary for expression of PEBP genes. Thirty-one $P E B P$ promoters contained light- responsive element Box 4, except for the $F T$-like gene AraipYA5YU (Additional file 6). In addition, the types and numbers of cis-acting elements showed diverse distribution among the PEBP promoters (Table 3 and Additional file 6), suggesting that $P E B P$ genes are functionally diverse and might work in different signaling pathways.

\section{Wild peanut PEBP gene expression patterns in multiple tissues}

To further investigate the potential functions of wild peanut $P E B P$ genes, $P E B P$ gene transcription patterns were analyzed in 22 different tissues using the datasets

Table 3 Cis-acting elements in the promoter region of each wild peanut PEBP gene

\begin{tabular}{|c|c|c|c|c|c|c|c|c|}
\hline Gene name & $\begin{array}{l}\text { Gene } \\
\text { Family }\end{array}$ & $\begin{array}{l}\text { Development } \\
\text { related elements }\end{array}$ & $\begin{array}{l}\text { Environmental stress } \\
\text { related elements }\end{array}$ & $\begin{array}{l}\text { Hormone- } \\
\text { responsive } \\
\text { elements }\end{array}$ & $\begin{array}{l}\text { Light- } \\
\text { responsive } \\
\text { elements }\end{array}$ & $\begin{array}{l}\text { Promoter } \\
\text { related } \\
\text { elements }\end{array}$ & $\begin{array}{l}\text { Site-binding } \\
\text { related elements }\end{array}$ & Others \\
\hline AraduEHZgY & FT-like & 0 & 1 & 5 & 10 & 2 & 0 & 16 \\
\hline AraduF950M & TFL 1-like & 1 & 0 & 5 & 9 & 2 & 0 & 12 \\
\hline AraduZ8JSI & MFT-like & 3 & 2 & 3 & 8 & 2 & 1 & 18 \\
\hline AraduA9H9T & FT-like & 2 & 2 & 3 & 9 & 2 & 0 & 12 \\
\hline AraduA4ISL & FT-like & 0 & 1 & 4 & 6 & 3 & 0 & 18 \\
\hline Aradu1I7E9 & FT-like & 0 & 3 & 5 & 6 & 2 & 1 & 17 \\
\hline AraduP7QP3 & TFL 1-like & 1 & 2 & 1 & 7 & 2 & 1 & 13 \\
\hline AraduWY2NX & TFL 1-like & 2 & 2 & 5 & 7 & 2 & 0 & 12 \\
\hline Aradu80YRY & $F T$-like & 2 & 2 & 5 & 9 & 2 & 0 & 13 \\
\hline AraduA6WCN & FT-like & 2 & 1 & 1 & 5 & 3 & 1 & 15 \\
\hline AraduRJP5K & TFL 1-like & 0 & 1 & 5 & 8 & 2 & 2 & 18 \\
\hline AraduQIZ46 & MFT-like & 2 & 1 & 5 & 7 & 2 & 2 & 17 \\
\hline AraduGONJW & FT-like & 1 & 1 & 3 & 7 & 2 & 0 & 13 \\
\hline Aradu60NUI & MFT-like & 1 & 2 & 4 & 9 & 2 & 1 & 15 \\
\hline Aradu23179 & MFT-like & 2 & 1 & 5 & 7 & 2 & 1 & 15 \\
\hline AraduYY72S & FT-like & 1 & 1 & 3 & 8 & 2 & 0 & 14 \\
\hline Araip344D4 & TFL1-like & 2 & 1 & 4 & 4 & 2 & 0 & 13 \\
\hline AraipWF9GZ & MFT-like & 4 & 3 & 5 & 8 & 2 & 0 & 19 \\
\hline AraipPC28F & $F T$-like & 1 & 1 & 4 & 6 & 2 & 0 & 12 \\
\hline AraipU9HL1 & $F T$-like & 0 & 1 & 5 & 6 & 2 & 2 & 19 \\
\hline AraipTISIZ & FT-like & 1 & 3 & 3 & 6 & 2 & 1 & 13 \\
\hline AraipYA5YU & $F T$-like & 0 & 3 & 4 & 9 & 2 & 1 & 16 \\
\hline AraipA5PDN & TFL 1-like & 1 & 1 & 3 & 6 & 2 & 2 & 17 \\
\hline Araip4V81G & TFL 1-like & 3 & 1 & 4 & 6 & 2 & 0 & 16 \\
\hline AraipZJ9GZ & FT-like & 0 & 3 & 2 & 8 & 2 & 2 & 21 \\
\hline AraipV23ZE & FT-like & 2 & 2 & 2 & 8 & 2 & 0 & 10 \\
\hline Araip03WUR & FT-like & 3 & 2 & 4 & 5 & 2 & 1 & 14 \\
\hline AraipT6XJY & TFL1-like & 2 & 3 & 5 & 9 & 3 & 0 & 18 \\
\hline AraipWWI38 & FT-like & 0 & 1 & 3 & 9 & 2 & 0 & 13 \\
\hline AraipA8S33 & MFT-like & 1 & 4 & 7 & 9 & 2 & 1 & 17 \\
\hline AraipVOBOS & MFT-like & 0 & 3 & 5 & 8 & 2 & 0 & 16 \\
\hline AraipVEP8T & FT-like & 1 & 2 & 4 & 7 & 2 & 0 & 14 \\
\hline
\end{tabular}


of the A. hypogaea gene expression mapped to A. duranensis and $A$. ipaensis $[51,52]$. The expression levels of several randomly selected $P E B P$ genes were checked in several wild peanut and cultivated peanut tissues and found that their expression patterns were similar to the published datasets (Additional file 7). Many wild peanut $P E B P$ genes showed tissue specific expression profiles. For example, all of the $M F T$-like members, including 4 AdPEBP members (Aradu60NUI, AraduQIZ46, Aradu23179, and AraduZ8JSI), and 3 AiPEBP genes (AraipVOBOS, AraipWF9GZ and AraipA8S33), were highly abundant in seeds, suggesting they may function in seed growth and development (Fig. 6). The FT-like gene AraipZJ9GZ showed high expression levels in lateral stem leaves, vegetative shoot tips, and reproductive shoot tips. In contrast, 5 FT-like members, including 2 AdPEBP genes (Aradu1I7E9 and AraduA4ISL) and 3 AiPEBP genes (AraipWWI38, AraipYA5YU, and AraipV23ZE), were expressed at low levels in all tested tissues (Fig. 6), suggesting that they might have weak or no function in flowering time regulation. Duplicated gene pair expressions were also investigated and some duplicated gene pairs showed similar expression patterns in some tissues (Fig. 6). For example, Aradu80YRY and AraduEHZ9Y showed similar expression levels in flowers, and AraduWY2NX and AraduF950M closely resembled each other in the reproductive shoot tip, suggesting they may have similar functions in these tissues. In contrast, some duplicated gene pairs showed distinct expression patterns. For example, AraduA6WCN was expressed at high levels in the vegetative shoot tip and stalk pt1, while its duplicated gene, AraduA4ISL, had low expression levels in all of the tested tissues (Fig. 6), suggesting functional divergence during evolution. Because many wild peanut $P E B P$ genes were orthologous with cultivated peanut $P E B P$ genes (Additional file 8), orthologous gene expression levels were compared. Many orthologous genes had similar expression levels. For example, AraipYA5YU/ArahyFW8Z6T, AraipWWI38/ Arahy5H2LSK, and Aradu1I7E9/ArahyXGVA1E had similar expression patterns in most of the tested tissues (Additional file 9).

Expression analysis of wild peanut PEBPs under long day and short day conditions during different growth phases Many light-responsive cis-acting elements were found in wild peanut $P E B P$ promoter regions. Thus, the $P E B P$ gene expressions were investigated in wild peanuts under different photoperiods during different growth phases. At some growth stages, different photoperiods changed the expression patterns of most PEBP genes (Figs. 7 and 8), suggesting they displayed important roles in light responsiveness during related stages of

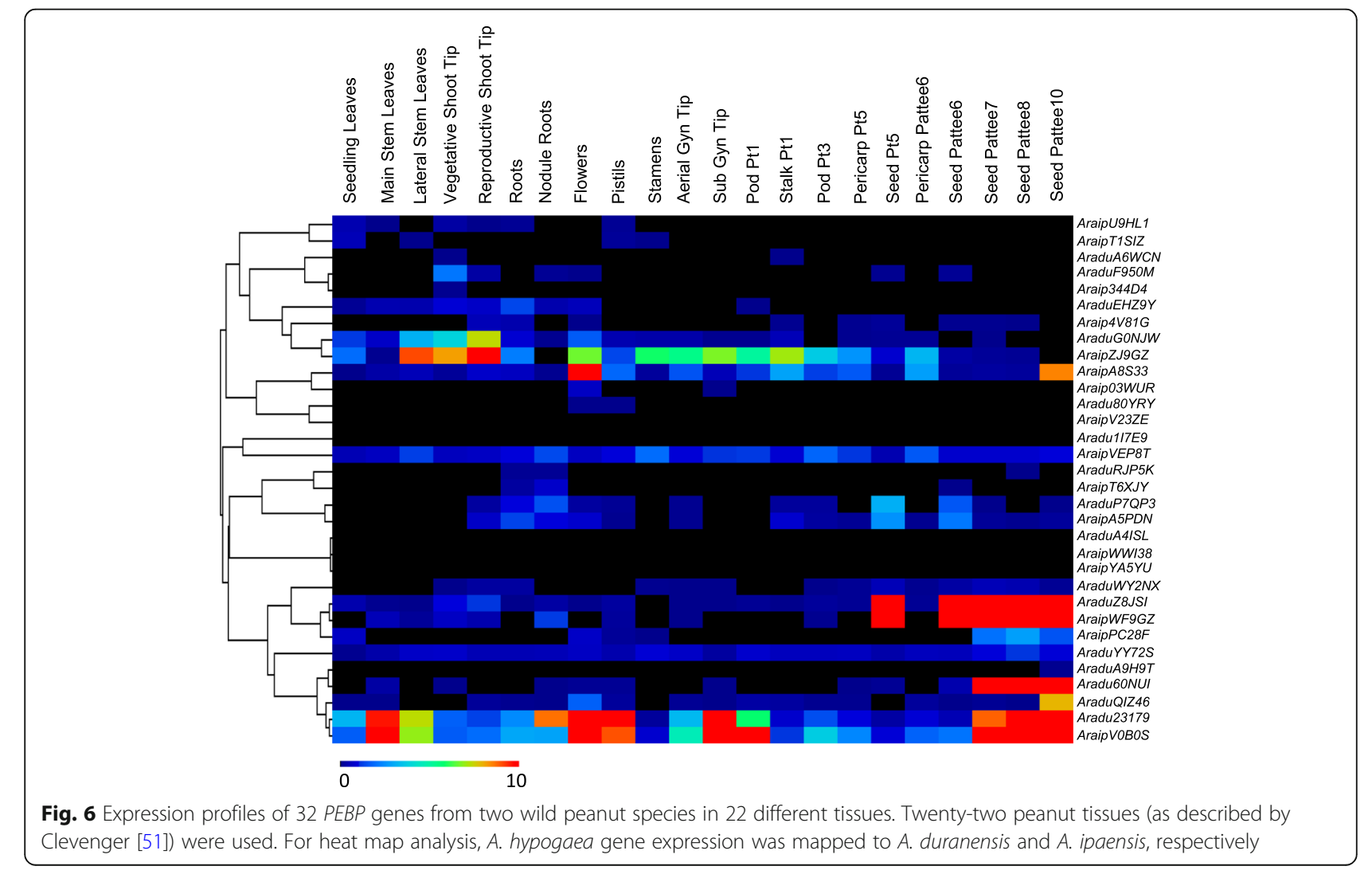



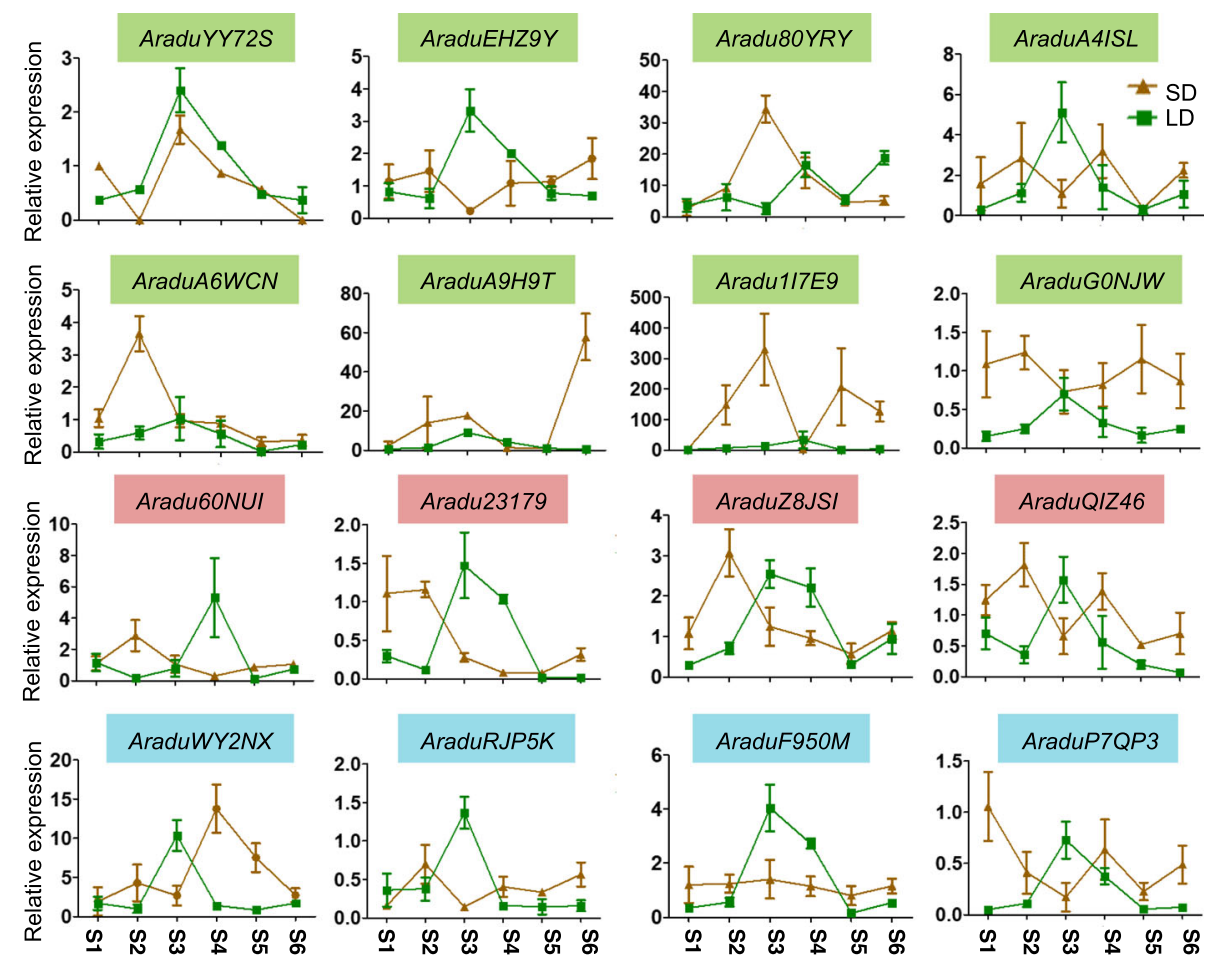

Fig. 7 A. duranensis leaf PEBP gene expression levels under long day and short day photoperiods. LD, long day; SD, short day. The growth conditions were set as $16 \mathrm{~h}$ light/8 h dark and $10 \mathrm{~h}$ light/14 $\mathrm{h}$ dark cycles for the long day and short day photoperiods, respectively. The expression levels of each gene were determined relative to an actin-expressing gene. Each sample was analyzed using three biological replicates
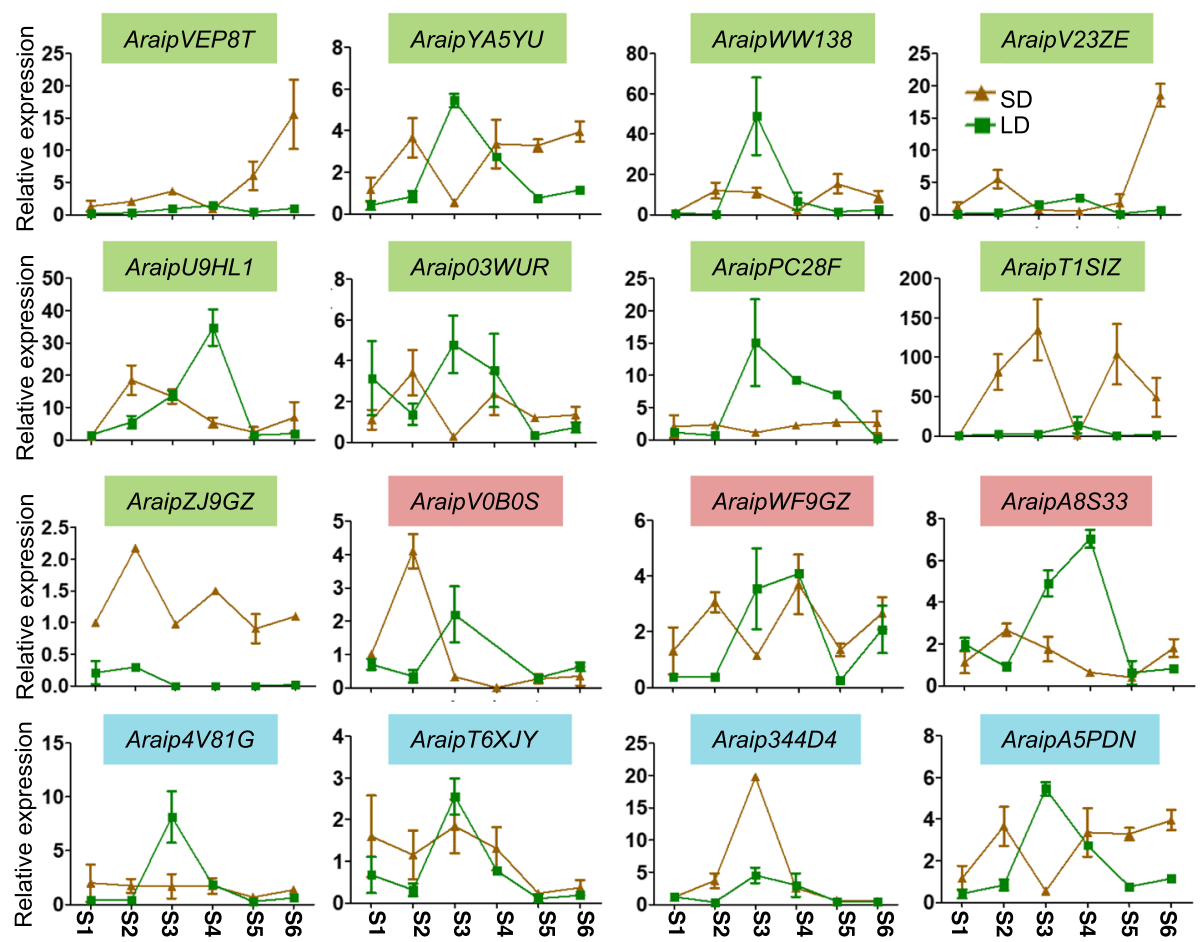

Fig. 8 A. ipaensis leaf PEBP gene expression levels under long day and short day photoperiods. LD, long day; SD, short day. The growth conditions were set as $16 \mathrm{~h}$ light/8 h dark and $10 \mathrm{~h}$ light/14 $\mathrm{h}$ dark cycles for the long day and short day photoperiods, respectively. The expression levels of each gene were determined relative to an actin-expressing gene. Each sample was analyzed using three biological replicates 
development. Some PEBP genes showed consistent expression levels during all growth phases under long day conditions, including AraduA6WCN, AraduA9H9T, and Aradu1I7E9 in A. duranensis, and AraipVEP8T, AraipV23ZE, AraipT1SIZ, and AraipZJ9GZ in A. ipaensis, all of which belong to the FT-like sub-family (Figs. 2, 7 and 8). Under the short day photoperiod, AraduF950M, AraipPC28F, and Araip4V81G showed consistent expression levels in different growth phases (Figs. 7 and 8). In addition, the expression of AraipZJ9GZ was higher under short day conditions than under long day conditions in all tested growth stages (Fig. 8). Some duplicated gene pairs displayed similar expression patterns throughout the growth phases under long day conditions, such as AraduYY72S/AraduEHZ9Y and AraipWWI38/AraipYA5YU (Figs. 7 and 8), suggesting these duplicated genes may be functionally redundant.

\section{Discussion}

Characterization of $P E B P$ genes has greatly increased our knowledge of the molecular mechanisms regulating flowering time and plant architecture in many plant species $[8,18-20]$. Peanut is an important oilseed crop worldwide, and the identification of peanut $P E B P$ genes helps to further our functional understanding of peanut flowering time and plant architecture regulation. Additionally, the investigation of wild peanut PEBP genes provides essential information for further functional characterization of related genes in cultivated peanuts $[40,41]$. In our study, thirty-two PEBP genes were identified and characterized from two wild peanut genomes.

Different plant species have different numbers of $P E B P$ genes $[8,18,19]$. Each of the two diploid wild peanut species, $A$. duranensis and A. ipaensis, has 16 PEBP genes (Table 1). The allotetraploid cultivated peanut is thought to be derived from hybridization and polyploidization of the two diploid wild species, and the genome size of $A$. hypogaea is close to the sum of $A$. duranensis and $A$. ipaensis genomes [36-39]. The $A$. hypogaea genome contains $31 P E B P$ members (Additional file 2), which is also close to the sum of the PEBP genes in the $A$. duranensis and $A$. ipaensis genomes. The two wild peanut genomes contain 8 TFL1-like, 17 FT-like, and 7 MFT-like members (Fig. 2 and Table 1), while the A. hypogaea genome contains 8 TFL1-like, 16 FT-like, and 7 MFT-like members (Additional file 2). Likely, one of the FT-like genes in $A$. hypogaea was lost during evolution. In addition, Arabidopsis, rice, soybean, and maize have 6, 19, 23, and 24 PEBP members, respectively [8, 18, 19]. The genome sizes of $A$. duranensis, A. ipaensis, A. hypogaea, Arabidopsis, rice, soybean, and maize are $1.25 \mathrm{~Gb}, 1.56$ $\mathrm{Gb}, 2.7 \mathrm{~Gb}, 125 \mathrm{Mb}, 466 \mathrm{Mb}, 1.1 \mathrm{~Gb}$, and $2.3 \mathrm{~Gb}$, respectively [40, 62-65]. Thus, the genome sizes in these plants are not correlated with the number of PEBP genes.

Gene duplication is particularly prevalent in plants and provides resources for novel gene functions. Some duplicated genes become pseudogenized and have no function, while other gene duplication pairs evolve new functions $[8,66]$. For example, duplicated PEBP genes in soybean have functionally diverged due to the alteration of critical amino acids [8]. Four interchromosomal duplications and one tandem duplication were identified in A. duranensis, and two interchromosomal duplications and one tandem duplication were found in A. ipaensis (Fig. 5). Some of these wild peanut duplicated gene pairs showed similar expression patterns, while the expression levels of others differed across tissues or growth phases (Figs. 6, 7 and 8). For example, Aradu80YRY/AraduEHZ9Y and AraduWY2NX/AraduF950M showed similar expression levels in the reproductive shoot tip, suggesting the functional conservation of these genes. In contrast, expression of Ara$d u A 6 W C N$ was high in the vegetative shoot tip and stalk pt1, while its duplicate, AraduA4ISL, had low expression levels in those two tissues (Fig. 6), suggesting functional divergence of these duplicated $P E B P$ genes.

Among these PEBP members, FT and TFL1 are well studied in many species [1]. The regulation of flowering time by $F T$ has been highly investigated. The FT-like genes Aradu80YRY, AraduYY72S, and AraduEHZ9Y in A. duranensis, and AraipV23ZE, AraipVEP8T, AraipYA5YU, and AraipWWI38 in A. ipaensis, are highly conserved with Arabidopsis FT and TSF genes (Fig. 2). However, AraipV23ZE, AraipYA5YU, and AraipWWI38 had very low expression levels in all tested tissues (Fig. 6). It is likely that Aradu80YRY, AraduYY72S, and AraduEHZ9Y in A. duranensis and AraipVEP8T in A. ipaensis have important roles in flowering time regulation. TFL1 is one of the most important genes involved in plant architecture regulation. Genes homologous to TFL1 have been shown to be involved in plant architecture regulation in many legumes, such as soybean (GmDt1), common bean (PvTFL1y), and mungbean (VrDet1), and these three genes are syntelogs [1, 58-61]. Synteny between AraduF950M/AraduWY2NX, Araip344D4/Araip4V81G, GmDt1, and PvTFL1y were observed in A. duranensis and A. ipaensis, respectively (Additional file 5), suggesting that they function in plant architecture regulation. There is only one TFL1 gene involved in plant architecture regulation in soybean, common bean, and mungbean. Although two genes have synteny with soybean GmDt1 and common bean PvTFL1y in $A$. duranensis and A. ipaensis, respectively, it is possible that there is only one key member involved in plant architecture regulation in either of the two wild peanut species. $M F T$ has an important role in seed germination via the abscisic acid and gibberellic acid pathways [34, 35]. In wild peanuts, MFT-like PEBP members were expressed at 
higher levels in seeds than in other tissues (Fig. 6), suggesting that these genes might play critical roles in seed development and seed germination pathways. Future work is needed to fully elucidate the involvement of $P E B P$ genes in flowering time and plant architecture regulation pathways in wild peanuts.

Cis-acting elements are important factors that bind transcription factors and active gene expression. Peanut PEBP promoter regions were found to contain a variety of cis-acting elements, including developmental elements, environmental stress related elements, hormone-responsive elements, light-responsive elements, promoter related elements, and site-binding related elements (Table 3 and Additional file 6). This suggests that PEBP genes might have critical roles in these signal pathways. Additionally, expression patterns of $P E B P$ genes varied in different tissues and different growth phases (Figs. 6, 7 and 8), further supporting functional differences. All of the PEBP genes contained light-responsive elements, and most of the peanut $P E B P$ genes showed altered expression patterns under long day versus short day growth conditions (Figs. 7, 8 and Table 3), indicating that they might be involved in plant development via photoperiod dependent pathways. Although most of the FT-like genes contained these 6 types of functional cis-acting elements (Table 3 and Additional file 6), 10 FT-like members had either low expression levels in different tissues or unchanged expression levels across growth stages under long day conditions (Figs. 6, 7 and 8). This could be due to the fact that these genes have weak or no function in these tissues or growth stages under long day photoperiod conditions. Some PEBP members, such as FT-like genes $[1,23,49]$, are circadian clock genes and might be expressed at other times of day that were not tested in this study. Moreover, the FT-like gene AraipZJ9GZ showed higher expression levels under short day conditions (Fig. 8), suggesting that AraipZJ9GZ is involved in flowering time regulation under short day rather than long day conditions. In all, the variation in cis-element numbers and gene expression patterns of $F T$-like genes likely reflects their functional diversities in flowering time regulation. TFL1-like and $M F T$-like $P E B P$ genes are likely similarly diverse in other functional pathways. Additionally, many wild peanut PEBP genes were found to be orthologous to cultivated peanut genes (Additional file 8), thus, the expression patterns of wild peanut $P E B P$ genes can be used to deduce $P E B P$ gene expression in A. hypogaea during growth phases under long day and short day conditions.

\section{Conclusions}

Genome-wide analysis was used to identify and characterize 16 PEBP genes from each of the two diploid wild peanut species, A. duranensis and A. ipaensis. Many characteristics of these $P E B P$ genes were investigated, including chromosomal distributions, gene structures, and motifs. The 32 PEBP genes were classified into TFL1like, $F T$-like, and $M F T$-like sub-families. Interchromosomal duplicated gene pairs and tandem duplication events were identified in both wild peanut species. In addition, four genes that are likely to play important roles in plant architecture and another four that likely regulate flowering time were identified. Ninety-five cisacting elements were identified, 56 of which have putative functions and may be responsible for tissue and photoperiod expression pattern differences. Detailed understanding of wild peanut $P E B P$ genes will be useful for future efforts to modify peanut plant flowering time and plant architecture.

\section{Supplementary information}

Supplementary information accompanies this paper at https://doi.org/10. 1186/s12870-019-2113-3.

Additional file 1. Subcellular localizations of PEBP proteins in tobacco leaf cells.

Additional file 2. Evolutionary relationship analysis of PEBP proteins from wild and cultivated peanuts.

Additional file 3. Alignment of wild peanut PEBP domains. The wathet, chrysoidine, and aqua colors indicate TFL 7-like, MFT-like and FT-like subfamilies, respectively.

Additional file 4. Sequence logos of 15 motifs in wild peanut PEBP proteins. The "sites" and "width" indicate the number of wild peanut PEBP proteins containing each motif and the amino acid number of each motif, respectively.

Additional file 5. Synteny analysis between soybean GmDt1, common bean PVTFL1y, and wild peanut TFL 1-like genes. Syntenic regions surrounding the analyzed homologous genes between soybean, common bean, and wild peanuts were investigated. (a) Synteny analysis between AraduRJP5K, AraipT6XJY, and GmDt1 (Glyma19g194300), and PvTFL1y (Phvul001g189200). (b) Synteny analysis between AraduF950M, Araip344D4, GmDt1, and PVTFL1y. (c) Synteny analysis between AraduWY2NX, Araip4V81G, GmDt1, and PVTFL1y. The red boxes indicate our target genes and the green boxes indicate genes surrounding the homologous genes. Gm, Glycine max; Pv, Phaseolus vulgaris.

Additional file 6. Functions of the cis-acting elements found in the promoter regions of wild peanut PEBP genes.

Additional file 7. Expression patterns of several wild and cultivated peanut PEBP genes.

Additional file 8. Wild and cultivated peanut orthologous genes.

Additional file 9. Expression profiles of PEBP genes in 22 different tissues from cultivated and wild peanut species.

Additional file 10. Primers used in this study.

\section{Abbreviations}

A. duranensis: Arachis duranensis; A. ipaensis: Arachis ipaensis; AA: Amino acid; ATC: Arabidopsis thaliana CENTRORADIALIS; BFT: BROTHER OF FT; CDS: Coding domain sequence; Chr: Chromosome number; FT: FLOWERING LOCUS T; Gm: Glycine max; GSDS: Gene Structure Display Server program; LD: Long day; SD, short day; MFT: MOTHER OF FT AND TFL1;

Mol.Wt: Molecular weight; N/A: Not applicable; NCBI: National Center for Biotechnology Information; PEBP: Phosphatidyl ethanolamine-binding protein; pl: Isoelectric point; PV: Phaseolus vulgaris; qRT-PCR: Quantitative realtime PCR; S1: Stage 1; S2: Stage 2; S3: Stage 3; S4: Stage 4; S5: Stage 5; S6: Stage 6; TFL1: TERMINAL FLOWER1; TSF: TWIN SISTER OF FT 


\section{Acknowledgements}

We thank Xiaojun Zhang at Qingdao Agricultural University for supplying wild peanut seeds PI219823 and PI468322.

\section{Author's contributions}

$\mathrm{SL}$ conceived and designed the research. $\mathrm{HJ}, \mathrm{XT}, \mathrm{MX}, \mathrm{HZ}$, JS and CC conducted the experiments and analyzed the data. SL wrote the manuscript. All authors read and approved the manuscript.

\section{Funding}

This work was supported by the National Natural Science Foundation of China (grant 31971898, 31601372), and the Qingdao Agricultural University Scientific Research Foundation (grant 6631115039, 6631119010). The funders had no role in the design of the study, collection, analysis, and interpretation of data, or in writing the manuscript.

\section{Availability of data and materials}

The datasets generated and analyzed during the current study are available from the corresponding author upon reasonable request.

\section{Ethics approval and consent to participate}

Not applicable.

\section{Consent for publication}

Not applicable.

\section{Competing interests}

The authors declare that they have no competing interests.

\section{Author details}

${ }^{1}$ College of Life Sciences, Key Lab of Plant Biotechnology in Universities of Shandong Province, Qingdao Agricultural University, Qingdao 266109, China. ${ }^{2}$ College of Agronomy, Qingdao Agricultural University, Qingdao 266109, China.

Received: 3 February 2019 Accepted: 31 October 2019

Published online: 09 November 2019

\section{References}

1. Wickland DP, Hanzawa Y. The FLOWERING LOCUS TTTERMINAL FLOWER 1 gene family: functional evolution and molecular mechanisms. Mol Plant. 2015;8(7):983-97.

2. Xu S, Chong K. Remembering winter through vernalisation. Nat Plants. 2018; 4(12):997-1009.

3. Beinecke FA, Grundmann L, Wiedmann DR, Schmidt FJ, Caesar AS, Zimmermann M, Lahme M, Twyman RM, Prufer D, Noll GA. The FT/FDdependent initiation of flowering under long-day conditions in the dayneutral species Nicotiana tabacum originates from the facultative short-day ancestor Nicotiana tomentosiformis. Plant J. 2018;96(2):329-42.

4. Eom H, Park SJ, Kim MK, Kim H, Kang H, Lee I. TAF15b, involved in the autonomous pathway for flowering, represses transcription of FLOWERING LOCUS C. Plant J. 2018;93(1):79-91.

5. Boss PK, Bastow RM, Mylne JS, Dean C. Multiple pathways in the decision to flower: enabling, promoting, and resetting. Plant Cell. 2004;16(Suppl):S18-31.

6. Jack T. Molecular and genetic mechanisms of floral control. Plant Cell. 2004; 16(Suppl):S1-17.

7. Baurle I, Dean C. The timing of developmental transitions in plants. Cell. 2006;125(4):655-64.

8. Wang Z, Zhou Z, Liu Y, Liu T, Li Q, Ji Y, Li C, Fang C, Wang M, Wu M, et al. Functional evolution of phosphatidylethanolamine binding proteins in soybean and Arabidopsis. Plant Cell. 2015;27(2):323-36.

9. Zheng XM, Wu FQ, Zhang X, Lin QB, Wang J, Guo XP, Lei CL, Cheng ZJ, Zou C, Wan J. Evolution of the PEBP gene family and selective signature on FTlike clade. J Syst Evol. 2016;54(5):502-10.

10. Schoentgen F, Jolles P. From structure to function: possible biological roles of a new widespread protein family binding hydrophobic ligands and displaying a nucleotide binding site. FEBS Lett. 1995;369(1):22-6.

11. Bradley D, Carpenter R, Copsey L, Vincent C, Rothstein S, Coen E. Control of inflorescence architecture in antirrhinum. Nature. 1996;379(6568):791-7.

12. Banfield MJ, Barker JJ, Perry AC, Brady RL. Function from structure? The crystal structure of human phosphatidylethanolamine-binding protein suggests a role in membrane signal transduction. Structure. 1998;6(10): 1245-54.

13. Bernier I, Tresca JP, Jolles P. Ligand-binding studies with a $23 \mathrm{kDa}$ protein purified from bovine brain cytosol. Biochim Biophys Acta. 1986;871(1):19-23.

14. Yeung K, Seitz T, Li S, Janosch P, McFerran B, Kaiser C, Fee F, Katsanakis KD,

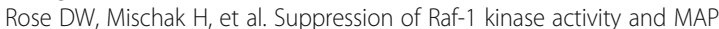
kinase signalling by RKIP. Nature. 1999;401(6749):173-7.

15. Chautard $H$, Jacquet M, Schoentgen F, Bureaud N, Benedetti H. Tfs $1 \mathrm{p}, \mathrm{a}$ member of the PEBP family, inhibits the Ira2p but not the Ira1p Ras GTPase-activating protein in Saccharomyces cerevisiae. Eukartot Cell. 2004;3(2):459-70.

16. Kobayashi Y, Kaya H, Goto K, Iwabuchi M, Araki T. A pair of related genes with antagonistic roles in mediating flowering signals. Science. 1999; 286(5446):1960-2.

17. Kardailsky I, Shukla VK, Ahn JH, Dagenais N, Christensen SK, Nguyen JT, Chory J, Harrison MJ, Weigel D. Activation tagging of the floral inducer FT. Science. 1999;286(5446):1962-5.

18. Chardon F, Damerval C. Phylogenomic analysis of the PEBP gene family in cereals. J Mol Evol. 2005;61(5):579-90.

19. Danilevskaya ON, Meng X, Hou Z, Ananiev EV, Simmons CR. A genomic and expression compendium of the expanded PEBP gene family from maize. Plant Physiol. 2008;146(1):250-64

20. Zhang $X$, Wang C, Pang C, Wei H, Wang H, Song M, Fan S, Yu S. Characterization and functional analysis of PEBP family genes in upland cotton (Gossypium hirsutum L.). PLoS One. 2016;11(8):e0161080.

21. Karlgren A, Gyllenstrand N, Kallman T, Sundstrom JF, Moore D, Lascoux M, Lagercrantz $U$. Evolution of the PEBP gene family in plants: functional diversification in seed plant evolution. Plant Physiol. 2011;156(4):1967-77.

22. Leeggangers $H$, Rosilio-Brami T, Bigas-Nadal J, Rubin N, van Dijk ADJ. Nunez de Caceres Gonzalez FF, Saadon-Shitrit S, Nijveen H, Hilhorst HWM, Immink RGH et al: Tulipa gesneriana and Lilium longiflorum PEBP genes and their putative roles in flowering time control. Plant Cell Physiol. 2018;59(1):90-106.

23. Navarro C, Cruz-Oro E, Prat S. Conserved function of FLOWERING LOCUS T (FT) homologues as signals for storage organ differentiation. Curr Opin Plant Biol. 2015;23:45-53.

24. Putterill J, Varkonyi-Gasic E. FT and florigen long-distance flowering control in plants. Curr Opin Plant Biol. 2016;33:77-82.

25. Abe M, Kobayashi $Y$, Yamamoto S, Daimon $Y$, Yamaguchi A, Ikeda $Y$, Ichinoki $H$, Notaguchi M, Goto K, Araki T. FD, a bZIP protein mediating signals from the floral pathway integrator FT at the shoot apex. Science. 2005;309(5737):1052-6.

26. Corbesier L, Vincent C, Jang S, Fornara F, Fan Q, Searle I, Giakountis A, Farrona S, Gissot L, Turnbull C, et al. FT protein movement contributes to long-distance signaling in floral induction of Arabidopsis. Science. 2007; 316(5827):1030-3.

27. Notaguchi M, Abe M, Kimura T, Daimon Y, Kobayashi T, Yamaguchi A, Tomita Y, Dohi K, Mori M, Araki T. Long-distance, graft-transmissible action of Arabidopsis FLOWERING LOCUS T protein to promote flowering. Plant Cell Physiol. 2008;49(11):1645-58.

28. Luo X, Gao Z, Wang Y, Chen Z, Zhang W, Huang J, Yu H, He Y. The NUCLEAR FACTOR-CONSTANS complex antagonizes Polycomb repression to de-repress FLOWERING LOCUS T expression in response to inductive long days in Arabidopsis. Plant J. 2018;95(1):17-29.

29. Luccioni L, Krzymuski M, Sanchez-Lamas M, Karayekov E, Cerdan PD, Casal JJ. CONSTANS delays Arabidopsis flowering under short days. Plant J. 2018. https://doi.org/10.1111/tpj.14171.

30. Yamaguchi A, Kobayashi Y, Goto K, Abe M, Araki T. TWIN SISTER OF FT (TSF) acts as a floral pathway integrator redundantly with FT. Plant Cell Physiol. 2005:46(8):1175-89.

31. Bradley D, Ratcliffe O, Vincent C, Carpenter R, Coen E. Inflorescence commitment and architecture in Arabidopsis. Science. 1997;275(5296):80-3.

32. Huang NC, Jane WN, Chen J, Yu TS. Arabidopsis thaliana CENTRORADIALIS homologue (ATC) acts systemically to inhibit floral initiation in Arabidopsis. Plant J. 2012;72(2):175-84.

33. Yoo SJ, Chung KS, Jung SH, Yoo SY, Lee JS, Ahn JH. BROTHER OF FT AND TFL1 (BFT) has TFL1-like activity and functions redundantly with TFL 1 in inflorescence meristem development in Arabidopsis. Plant J. 2010;63(2):241-53.

34. Yoo SY, Kardailsky I, Lee JS, Weigel D, Ahn JH. Acceleration of flowering by overexpression of MFT (MOTHER OF FT AND TFL1). Mol Cells. 2004; 17(1):95-101. 
35. Xi W, Liu C, Hou X, Yu H. MOTHER OF FT AND TFL1 regulates seed germination through a negative feedback loop modulating ABA signaling in Arabidopsis. Plant Cell. 2010;22(6):1733-48.

36. Kochert G, Stalker HT, Gimenes M, Galgaro L, Romero-Lopes C, Moore K. RFLP and cytogenetic evidence on the origin and evolution of all otetraploid domesticated peanut, Arachis hypogaea (Leguminosae). Am J Bot. 1996;83:1282-91.

37. Freitas FO, Moretzsohn MC, Valls JF. Genetic variability of Brazilian Indian landraces of Arachis hypogaea L. Genet Mol Res. 2007;6(3):675-84.

38. Moretzsohn MC, Gouvea EG, Inglis PW, Leal-Bertioli SC, Valls JF, Bertioli DJ: A study of the relationships of cultivated peanut (Arachis hypogaea) and its most closely related wild species using intron sequences and microsatellite markers. Ann Bot 2013; 111(1):113-126.

39. Wang P, Gao C, Bian X, Zhao S, Zhao C, Xia H, Song H, Hou L, Wan S, Wang $X$. Genome-wide identification and comparative analysis of cytosine-5 DNA methyltransferase and demethylase families in wild and cultivated peanut. Front Plant Sci. 2016;7:7.

40. Bertioli DJ, Cannon SB, Froenicke L, Huang G, Farmer AD, Cannon EK, Liu X, Gao D, Clevenger J, Dash S, et al. The genome sequences of Arachis duranensis and Arachis ipaensis, the diploid ancestors of cultivated peanut. Nat Genet. 2016;48(4):438-46.

41. Chen X, Li H, Pandey MK, Yang Q, Wang X, Garg V, Li H, Chi X, Doddamani $D$, Hong $Y$, et al. Draft genome of the peanut A-genome progenitor (Arachis duranensis) provides insights into geocarpy, oil biosynthesis, and allergens. Proc Natl Acad Sci U S A. 2016:113(24):6785-90.

42. Kumar S, Stecher G, Tamura K. MEGA7: molecular evolutionary genetics analysis version 7.0 for bigger datasets. Mol Biol Evol. 2016;33(7):1870-4

43. Li S, Wang RH, Jin HQ, Ding YH, CM C. Molecular characterization and expression profile analysis of heat shock transcription factors in mungbean. Front Genet. 2019:9:736.

44. Hu B, Jin J, Guo AY, Zhang H, Luo J, Gao G. GSDS 2.0: an upgraded gene feature visualization server. Bioinformatics. 2015;31(8):1296-7.

45. Zhang $D$, Zhao M, Li S, Sun L, Wang W, Cai C, Dierking EC, Ma J. Plasticity and innovation of regulatory mechanisms underlying seed oil content mediated by duplicated genes in the palaeopolyploid soybean. Plant J. 2017;90(6):1120-33.

46. Krzywinski M, Schein J, Birol I, Connors J, Gascoyne R, Horsman D, Jones SJ, Marra MA. Circos: an information aesthetic for comparative genomics. Genome Res. 2009;19(9):1639-45.

47. Hou L, Zhang Z, Dou S, Zhang Y, Pang X, Li Y. Genome-wide identification, characterization, and expression analysis of the expansin gene family in Chinese jujube (Ziziphus jujuba Mill.). Planta. 2019;249(3):815-29.

48. Lescot M, Dehais P, Thijs G, Marchal K, Moreau Y, Van de Peer Y, Rouze P, Rombauts S. PlantCARE, a database of plant cis-acting regulatory elements and a portal to tools for in silico analysis of promoter sequences. Nucleic Acids Res. 2002;30(1):325-7.

49. Li S, Ying Y, Secco D, Wang C, Narsai R, Whelan J, Shou H. Molecular interaction between PHO2 and GIGANTEA reveals a new crosstalk between flowering time and phosphate homeostasis in Oryza sativa. Plant Cell Environ. 2017;40(8):1487-99.

50. Sui J, Li R, Fan Q, Song L, Zheng C, Wang J, Qiao L, Yu S. Isolation and characterization of a stress responsive small GTP-binding protein AhRabG3b in peanut (Arachis hypogaea L.). Euphytica. 2013;189:161-72.

51. Clevenger J, Chu Y, Scheffler B, Ozias-Akins P. A developmental transcriptome map for allotetraploid Arachis hypogaea. Front Plant Sci. 2016;7:1446.

52. Dash S, Cannon EKS, Kalberer SR, Farmer AD, SB. C: PeanutBase and other bioinformatic resources for peanut (Chapter 8). In Peanuts Genetics, Processing, and Utilization, edited by Stalker HT and WilsonvRF. AOCS Press. 2016: 241-252.ISBN 9781630670382

53. Song H, Guo Z, Chen T, Sun J, Yang G. Genome-wide identification of LRRcontaining sequences and the response of these sequences to nematode infection in Arachis duranensis. BMC Plant Biol. 2018;18(1):279.

54. Song $H$, Wang $P$, Lin JY, Zhao $C$, Bi $Y$, Wang $X$. Genome-wide identification and characterization of WRKY gene family in peanut. Front Plant Sci. 2016;7:534.

55. Wang P, Song H, Li C, Li P, Li A, Guan H, Hou L, Wang X. Genome-wide dissection of the heat shock transcription factor family genes in Arachis. Front Plant Sci. 2017:8:106.

56. Ding $M$, Chen J, Jiang $Y$, Lin L, Cao Y, Wang M, Zhang Y, Rong J, Ye W. Genome-wide investigation and transcriptome analysis of the WRKY gene family in Gossypium. Mol Gen Genomics. 2015;290(1):151-71.
57. Adams KL, Wendel JF. Polyploidy and genome evolution in plants. Curr Opin Plant Biol. 2005;8(2):135-41

58. Tian Z, Wang X, Lee R, Li Y, Specht JE, Nelson RL, McClean PE, Qiu L, Ma J. Artificial selection for determinate growth habit in soybean. Proc Natl Acad Sci U S A. 2010;107(19):8563-8.

59. Liu B, Watanabe S, Uchiyama T, Kong F, Kanazawa A, Xia Z, Nagamatsu A, Arai M, Yamada T, Kitamura K, et al. The soybean stem growth habit gene Dt1 is an ortholog of Arabidopsis TERMINAL FLOWER1. Plant Physiol. 2010; 153(1):198-210.

60. Repinski SL, Kwak M, Gepts P. The common bean growth habit gene PVTFL1y is a functional homolog of Arabidopsis TFL1. Theor Appl Genet. 2012;124(8):1539-47.

61. Li S, Ding Y, Zhang D, Wang X, Tang X, Dai D, Jin H, Lee SH, Cai C, Ma J. Parallel domestication with a broad mutational spectrum of determinate stem growth habit in leguminous crops. Plant J. 2018;96(4):761-71.

62. Arabidopsis Genome I. Analysis of the genome sequence of the flowering plant Arabidopsis thaliana. Nature. 2000;408(6814):796-815.

63. Yu J, Hu S, Wang J, Wong GK, Li S, Liu B, Deng Y, Dai L, Zhou Y, Zhang X, et al. A draft sequence of the rice genome (Oryza sativa L. ssp. indica). Science. 2002;296(5565):79-92.

64. Schnable PS, Ware D, Fulton RS, Stein JC, Wei F, Pasternak S, Liang C, Zhang J, Fulton L, Graves TA, et al. The B73 maize genome: complexity, diversity, and dynamics. Science. 2009;326(5956):1112-5.

65. Schmutz J, Cannon SB, Schlueter J, Ma J, Mitros T, Nelson W, Hyten DL, Song Q, Thelen JJ, Cheng J, et al. Genome sequence of the palaeopolyploid soybean. Nature. 2010:463(7278):178-83.

66. Kondrashov FA, Rogozin IB, Wolf YI, Koonin EV. Selection in the evolution of gene duplications. Genome Biol. 2002;3(2):RESEARCH0008.

\section{Publisher's Note}

Springer Nature remains neutral with regard to jurisdictional claims in published maps and institutional affiliations.

Ready to submit your research? Choose BMC and benefit from:

- fast, convenient online submission

- thorough peer review by experienced researchers in your field

- rapid publication on acceptance

- support for research data, including large and complex data types

- gold Open Access which fosters wider collaboration and increased citations

- maximum visibility for your research: over $100 \mathrm{M}$ website views per year

At BMC, research is always in progress.

Learn more biomedcentral.com/submissions 